\title{
Regional left ventricular contraction abnormality during early systole in patients with angina pectoris Assessment with radionuclide ventriculography
}

\author{
TAKASHI YAMAGISHI, MASAHARU OZAKI, TOHRU IKEZONO, TATSURO SHIMIZU, \\ HIDEKI YAMAOKA, YUJI FURUTANI, YASUO MATSUDA, TOSHIAKI KUMADA, \\ REIZO KUSUKAWA
}

From the Second Department of Internal Medicine, University of Yamaguchi, Ube, fapan

SUMMARY To determine the presence and prevalence of regional contraction abnormalities in patients with angina pectoris, radionuclide ventriculography gated to an electrocardiogram was carried out in 22 control subjects (group 1) and in 22 patients with angina pectoris (group 2) with isolated stenosis of the left anterior descending coronary artery. No patients had had previous myocardial infarctions. A computer program subdivided the left ventricle into four regions at a geometric centre, and time-activity curves ( $30-40 \mathrm{~ms} /$ frame) of the global, septal, apical, and lateral regions were computed. There was no significant difference in the ejection fraction in the global or in any of the regions between the two groups. End systole in each region occurred close to global end

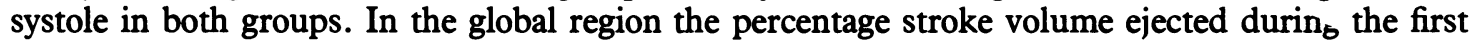
third of systole was not significantly less in group 2 than in group 1. Regional analysis of the segments perfused by the stenosed vessel showed that the percentage stroke volume ejected during the first third of systole in group 2 was significantly less in the septal region and in the apical region compared with that in group 1 . In contrast, in the normally perfused lateral region, there was no significant difference in the percentage stroke volume at the first third of systole between the two groups. This indicates that early contraction abnormalities are present in the region perfused by the stenosed vessel in patients with angina pectoris without previous myocardial infarction.

Thus analysing the regional change in left ventricular volume during ejection in patients with coronary artery disease can show localised areas of contraction abnormalities during early systole that are not apparent when ventricular contraction is assessed as a whole.

Left ventricular ejection fraction is usually normal in patients without previous myocardial infarction even in the presence of severe coronary artery disease. Since Noble et al using a conscious dog model, found that temporary coronary occlusion results in an appreciable depression of maximal acceleration of flow, ${ }^{1}$ the early phases of left ventricular ejection have been investigated to differentiate between patients with coronary artery disease, particularly those with a normal ejection fraction. Controversy exists, however, as to the presence and prevalence of contraction abnormalities in the early ejection phase in coronary

Requests for reprints to Dr Takashi Yamagishi, Second Department of Internal Medicine, University of Yamaguchi, Ube, 755 Japan.

Accepted for publication 23 August 1983 artery disease. ${ }^{2-13}$ With the recent development of computer technology, assessment of regional left ventricular function has become an established and widely applied non-invasive technique. ${ }^{12} 1415 \mathrm{We}$ used this computer assisted method to assess quantitatively regional left ventricular function. To evaluate the early ejection phase of the left ventricle by regions, we performed radionuclide ventriculography gated to electrocardiograms at rest in patients with single vessel disease but without myocardial infarction.

\section{Patients and methods}

STUDY POPULATION

The study group consisted of 44 subjects ( 30 male and 
14 female) referred to the Yamaguchi University Hospital in 1981 and 1982. All underwent electrocardiogram gated radionuclide ventriculography. They were classified as follows: group 1 consisted of 22 subjects who acted as controls (11 male and 11 female, age range 25-64 years); group 2 consisted of 22 patients with angina pectoris (19 male and three female, age range 47-68 years).

Of the 22 control subjects in group 1,11 underwent cardiac catheterisation for the evaluation of atypical chest pain and were found to have a normal left ventriculogram and coronary arteriogram and to have normal haemodynamic variables at rest and during the supine bicycle exercise test or ergonovine maleate test. In the remaining 11 subjects (normal volunteers) cardiac catheterisation was not performed, but physical examination (including blood pressure), chest radiography, electrocardiography, echocardiography, and stress myocardial scintigraphy with thallium-201 showed no abnormalities. Informed consent was obtained from all subjects in group 1 . All patients in group 2 underwent cardiac catheterisation. Of the 22 patients, 19 had severe organic stenosis $(>75 \%)$ in the luminal diameter of only the left anterior descending coronary artery. In the remaining three patients, coronary arteriography showed a normal coronary artery at rest, but the supine bicycle exercise or ergonovine maleate test produced spasm with total occlusion of the left anterior descending coronary artery accompanied simultaneously by chest pain and ST segment elevation on the electrocardiogram. No patient had a history or electrocardiographic or ventriculographic evidence of a previous myocardial infarction. Patients with congenital heart disease, hypertensive heart disease, arrhythmia, or cardiomyopathy were excluded from the study.

Radionuclide ventriculography was performed at least 72 hours after treatment with calcium antagonists or beta blockers had been stopped and at least 12 hours after treatment with nitrates. The test was performed during the seven days before or after cardiac catheterisation. There was no change in the clinical condition of the patients during the period between the two investigations. All patients were in normal sinus rhythm and had no conduction disturbances.

The radionuclide studies were preceded by resting myocardial scintigraphy with thallium-201 in both groups, and the tracer uptake defects were not seen on the resting images in any of the $\mathbf{4 4}$ patients.

\section{GATED RADIONUCLIDE VENTRICULOGRAPHY}

A conventional gamma camera (PHO/GAMMA LFOV, Searle Inc, Des Plaines, Illinois) equipped with a high resolution all purpose parallel-hole collimator was used for gated imaging. All patients were given $600-800 \mathrm{MBq}(15-20 \mathrm{mCi})$ of technetium-99m- labelled human serum albumin intravenously. After the radionuclide had equilibrated with the intravascular space (about 10 minutes), counts were acquired during 600 beats in multiple gate mode on magnetic disc with a digital computer (SCINTIPAC-1200, Shimadzu Seisakusho, Kyoto, Japan). Those photoevents falling within a $20 \%$ window centred on the photopeak of technetium-99m were recorded. The camera was positioned in the modified left anterior oblique projection ( $15^{\circ}$ caudal tilt). Low count (500 000 counts) scintigrams were acquired with a digital computer (Scintiview, Searle Inc) until the camera obliquity showing the greatest separation of the right and left ventricles was found (typically a $40-60^{\circ}$ projection). A computer based procedure gated to the electrocardiogram was used to collect and organise data into a series of images or frames (framing rate up to 31 frames/cardiac cycle) spanning the average cardiac cycle. Cardiac cycles that fell outside a range of acceptable cardiac cycle lengths selected by the physician were automatically excluded from analysis to prevent distortion of the time-activity curves.

The original multiple gated mode data were collected on magnetic disc by computer using a $64 \times 64$ matrix. The nth frame included those counts falling in a 30-40 ms window ending $\mathrm{n} \times 30-40 \mathrm{~ms}$ from any $R$ wave on the electrocardiogram. Each $30-40 \mathrm{~ms}$ frame contained more than 30000 counts within the left ventricle in the end diastolic frame in patients with a normal heart size. To improve visualisation of the left ventricular perimeter, a $50 \%$ threshold was imposed on each frame-that is, matrix cells containing fewer than $50 \%$ of the maximum cell counts in the image were set equal to zero. This enhanced first image, which corresponded to the first $30-40 \mathrm{~ms}$ frame immediately after the $\mathbf{R}$ wave, was defined as the end diastolic frame. A left ventricular longitudinal axis connecting the midpoint of the base and apex was rotated parallel to the $y$ coordinate of the digital matrix on the end diastolic frame, and the end diastolic perimeter of the left ventricle was traced manually with an electronic cursor. The end systolic frame was defined as the frame with the minimum counts within the end diastolic perimeter of the left ventricle. A crescent shaped background region of interest was traced with an electronic cursor along the lateral, api$\mathrm{cal}$, and septal regions of the end systolic ventricular perimeter on the end systolic frame, specifically avoiding regions of high count activity. A computer program determined a geometric centre of gravity of the end diastolic perimeter of the left ventricle and subdivided it into four regions (basal, septal, apical, and lateral) with two intersecting lines at an angle of $45^{\circ}$ to the longitudinal axis of the left ventricle at the geometric centre of gravity (Fig. 1). The background 


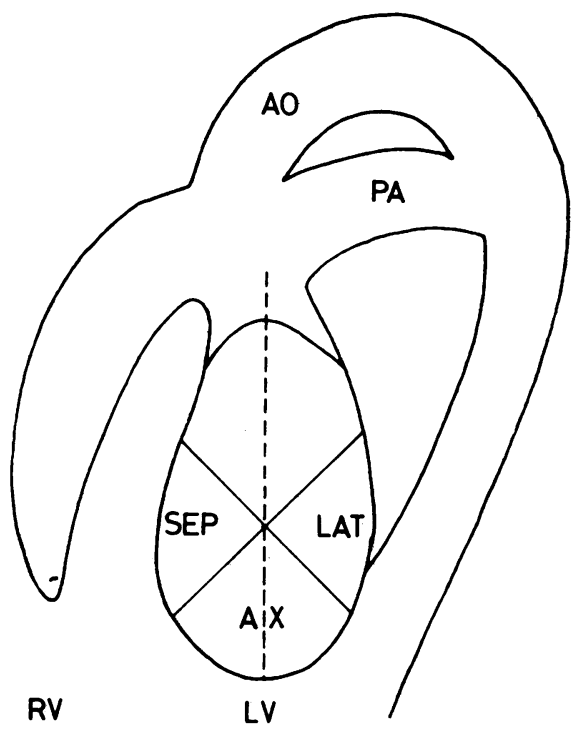

Fig. 1 Left ventricular region of interest at end diastole divided into four regions (basal, septal (SEP), apical (AX), and lateral (LAT)) at the geometric centre of gravity (dotted line). Basal region was excluded from analysis because of overlap with the aorta $(A O)$, left atrium, or the pulmonary artery $(P A)$.

correction for the region of the left ventricle was estimated using an average count per cell in the background region of interest obtained in the end systolic frame. Background corrected time-activity curves of global left ventricle and each of three regions (septal, apical, and lateral) were generated after three point temporal smoothing.

Immediately before the radionuclide study, the duration of the pre-ejection period was measured from a simultaneous recording of the electrocardiogram, the phonocardiogram, and the carotid arterial pulse tracing using a multichannel photographic system (ALOKA SSD-110S). Paper speed was $100 \mathrm{~mm} / \mathrm{s}$ and lead II of the electrocardiogram was used. A microphone was placed over the upper part of the precordium in a position optimal for recording the second heart sounds. The total electromechanical systolic interval $\left(\mathrm{QS}_{2}\right)$ was measured from the onset of the QRS complex to the first high frequency variations of the aortic component of the second heart sound, and the left ventricular ejection time was measured from the first upstroke to the trough of the incisura of the carotid pulse tracing. The duration of the pre-ejection period was derived by subtracting the left ventricular ejection time from the $\mathrm{QS}_{2}$ interval. ${ }^{16}$ Since the basal region of the left ventricle tended to overlie the regions of the mitral and aortic valves, aorta, left atrium, and great vessels this region was excluded from this study.
The following indices were obtained from the time-activity curves in the global left ventricle and in each of the three regions:

(1) Ejection fraction-EF (\%) $=100 \times(E D-E S) /$ $(\mathrm{ED}-\mathrm{BC})$, where $\mathrm{ED}, \mathrm{ES}$, and $\mathrm{BC}$ were end diastolic, end systolic, and background counts respectively.

(2) Time to end systole- the time interval between the electrocardiogram $R$ wave and frame with minimum counts.

(3) Percentage stoke volume ejected during the first or second third of systole-the fraction of the stroke volume ejected during the first or second third of ejection and expressed as a percentage of the stroke volume.

To determine the onset of ejection on the timeactivity curve, the interval from the onset of QRS to the instant of $R$ wave gating (peak negative $R$ to $S$ transition) was measured manually from the recording of the electrocardiogram obtained immediately before the radionuclide study, and this interval was subtracted from the duration of the pre-ejection period. The point measured from the first frame to the interval obtained above was chosen as the onset of ejection on the time-activity curve. The end of ejection was indicated by the frame with minimum counts recorded in the global left ventricle.

\section{REPRODUCIBILITY OF RADIONUCLIDE TECHNIQUE}

The reproducibility of radionuclide ventriculographic variables in measuring left ventricular systolic function was determined in 12 patients with various heart diseases (previous myocardial infarction (3), angina pectoris (3), hypertensive heart disease (3), valvular heart disease (2), and hypertrophic cardiomyopathy (1)). Two separate radionuclide studies performed 20-30 minutes apart were carried out at rest after a single injection of technetium- $99 \mathrm{~m}$. The patients rested in the supine position between the two studies. All the studies were performed at least $\mathbf{7 2}$ hours after all treatment had been stopped.

\section{ANGIOGRAPHY}

Coronary angiography was performed using the Sones method. Severe coronary artery disease was present when the luminal diameter was narrowed by $\geqslant 75 \%$. Biplane left ventricular cineangiograms were performed at $60 \mathrm{frames} / \mathrm{s}$ in a $30^{\circ}$ right anterior oblique projection and a $60^{\circ}$ left anterior oblique projection during sustained inspiration.

On replay of projected cineventriculograms, at least one normal cardiac cycle that showed maximum opacification (immediately after at least one normal non-ectopic beat) was selected for analysis of movement of the geometric centre of gravity. The end diastolic frame was selected visually as the frame that 
showed the largest projected ventricular area. The end systolic frame was selected as the frame that showed the smallest projected ventricular area. Left anterior oblique silhouettes of left ventricular end diastole and end systole were traced manually with an electronic cursor using the same digital computer as the one used in our radionuclide study (SCINTIPAC-1200, Shimadzu Seisakusho Ltd, Kyoto, Japan) from projected cineventriculograms superimposed on the same paper.

After the geometric centres of gravity had been defined at end systole and end diastole the path length traversed by the geometric centres during systole was obtained in 11 subjects in group 1 and in 22 patients in group 2. The geometric centre of gavity moved to some extent towards the anterosuperior chest wall in both groups, and the path length was $4.2 \pm 2.3 \mathrm{~mm}$ in group 1 and $4.3 \pm 2.3 \mathrm{~mm}$ in group 2 . There was no significant difference in the path length between the two groups. To compare patients whose heart size varied, the path length was normalised by dividing it by the end diastolic longitudinal diameter and expressing the result as a percentage. There was no significant difference in the normalised path length between the two groups $(7 \cdot 6 \pm 5 \cdot 2 \%$ (group 1 ) and $6 \cdot 7 \pm 4 \cdot 1 \%$ (group 2 ); NS).

\section{STATISTICAL ANALYSIS}

The data are expressed as means \pm 1 standard deviation (SD). The lower limit of the normal value was defined as the mean minus 2 SD. Statistical analysis was performed using the $t$ test for unpaired data. The level of statistical significance was $p<0.05$.
Accuracy of the radionuclide method in assessing regional left ventricular function

The main problem when assessing regional wall movement in various parts of the ventricle is the fixing of a reference point to which wall movement can be related. ${ }^{1718}$ As a reference point of the system, we chose the geometric centre of gravity of the end diastolic image and determined regional ventricular function by analysing the regional time-activity curves. If the reference point moves throughout the cardiac cycle, measurement of regional wall motion is avoided. ${ }^{17}$ Left ventricular segmental shortening is directed towards the centre of gravity, ${ }^{19}$ which is maintained at a relatively stable position throughout the cardiac cycle in patients with either normal or abnormal contractile dynamics. ${ }^{20-22}$ Ingels et al implanted radiopaque markers into the left ventricular myocardium of patients at surgery and studied the dynamics of the left ventricular centre of gravity throughout the cardiac cycle in the right anterior oblique projection. ${ }^{20}$ They found that movements from end diastole to end systole were $2.6 \pm 1.2 \mathrm{~mm}$ in normal hearts and $4.6 \pm 1.3 \mathrm{~mm}$ in abnormal hearts.

We also found that the path length traversed by the centre of gravity during systole was small relative to the left ventricular longitudinal axis in both groups. This finding by contrast ventriculography was obtained during breath holding. The time required to complete the radionuclide study was about 10 minutes. Movements of the centre of gravity that arise from extracardiac motion-for example, respiration or patient movement-must, therefore, be taken into account. Ingels et al reported that extracardiac motion

Table 1 Systolic phase indices in 22 control subjects (group 1) and in 22 patients with coronary artery disease (group 2). Values are means $\pm S D$

\begin{tabular}{|c|c|c|c|c|c|c|c|c|c|c|c|c|}
\hline \multirow{2}{*}{$\begin{array}{l}\text { Left } \\
\text { ventricular } \\
\text { regions }\end{array}$} & \multicolumn{3}{|c|}{ Ejection fraction (\%) } & \multicolumn{3}{|c|}{ Time to end systole (ms) } & \multicolumn{3}{|c|}{$\begin{array}{l}\% \text { Stroke volume } \\
\text { (at } 1 / 3 \text { systole) }\end{array}$} & \multicolumn{3}{|c|}{$\begin{array}{l}\% \text { Stroke volume } \\
\text { (at } 2 / 3 \text { systole) }\end{array}$} \\
\hline & Group I & Group 2 & $p$ & Group 1 & Group 2 & $p$ & Group 1 & Group 2 & $p$ & Group 1 & Group 2 & $p$ \\
\hline $\begin{array}{l}\text { Global } \\
\text { Septal } \\
\text { Apical } \\
\text { Lateral }\end{array}$ & $\begin{array}{l}58 \pm 3 \\
55 \pm 8 \\
85 \pm 8 \\
67 \pm 10\end{array}$ & $\begin{array}{l}58 \pm 6 \\
57 \pm 9 \\
86 \pm 10 \\
69 \pm 11\end{array}$ & $\begin{array}{l}\text { NS } \\
\text { NS } \\
\text { NS } \\
\text { NS }\end{array}$ & $\begin{array}{l}349 \pm 31 \\
344 \pm 31 \\
357 \pm 33 \\
357 \pm 30\end{array}$ & $\begin{array}{l}356 \pm 35 \\
347 \pm 42 \\
364 \pm 33 \\
373 \pm 31\end{array}$ & $\begin{array}{l}\text { NS } \\
\text { NS } \\
\text { NS } \\
\text { NS }\end{array}$ & $\begin{array}{l}38 \pm 4 \\
41 \pm 6 \\
37 \pm 5 \\
40 \pm 4\end{array}$ & $\begin{array}{l}38 \pm 6 \\
34 \pm 11 \\
32 \pm 6 \\
40 \pm 7\end{array}$ & $\begin{array}{l}\text { NS } \\
<0.01 \\
<0.02 \\
\text { NS }\end{array}$ & $\begin{array}{l}82 \pm 3 \\
81 \pm 6 \\
79 \pm 5 \\
80 \pm 5\end{array}$ & $\begin{array}{l}81 \pm 3 \\
83 \pm 6 \\
78 \pm 5 \\
79 \pm 5\end{array}$ & $\begin{array}{l}\text { NS } \\
\text { NS } \\
\text { NS } \\
\text { NS }\end{array}$ \\
\hline
\end{tabular}

Table 2 Correlation of results of radionuclide ventriculography from two studies ${ }^{\star}$ to assess left ventricular function in 22 patients with angina pectoris and 22 control subjects

\begin{tabular}{|c|c|c|c|c|c|c|c|c|c|c|c|c|}
\hline \multirow{3}{*}{$\begin{array}{l}\text { Left } \\
\text { ventricular } \\
\text { regions }\end{array}$} & \multirow{2}{*}{\multicolumn{3}{|c|}{ Ejection fraction (\%) }} & \multirow{2}{*}{\multicolumn{3}{|c|}{ Time to end systole (ms) }} & \multicolumn{6}{|c|}{$\%$ Stroke volume } \\
\hline & & & & & & & \multicolumn{3}{|c|}{ At $1 / 3$ systole } & \multicolumn{3}{|c|}{ At $2 / 3$ systole } \\
\hline & $r$ & $A$ & $\boldsymbol{B}$ & $r$ & $A$ & $\boldsymbol{B}$ & $r$ & $A$ & $B$ & $r$ & $\boldsymbol{A}$ & $\boldsymbol{B}$ \\
\hline $\begin{array}{l}\text { Global } \\
\text { Regional }\end{array}$ & $\begin{array}{l}0.98 \\
0.98\end{array}$ & $\begin{array}{l}0.98 \\
0.94\end{array}$ & $\begin{array}{l}4 \\
5\end{array}$ & $\begin{array}{l}0.97 \\
0.90\end{array}$ & $\begin{array}{l}1.00 \\
0.93\end{array}$ & $\begin{array}{l}2 \\
12\end{array}$ & $\begin{array}{l}0.94 \\
0.95\end{array}$ & $\begin{array}{l}1.01 \\
0.97\end{array}$ & $3^{-2}$ & $\begin{array}{l}0.96 \\
0.97\end{array}$ & $\begin{array}{l}0.98 \\
0.95\end{array}$ & $\begin{array}{l}3 \\
4\end{array}$ \\
\hline
\end{tabular}

r, correlation coefficient.

$\star$ Relation between results of the first (study 1) and second study (study 2) was (study 2$)=\mathbf{A} \times($ study 1$)+B$. 


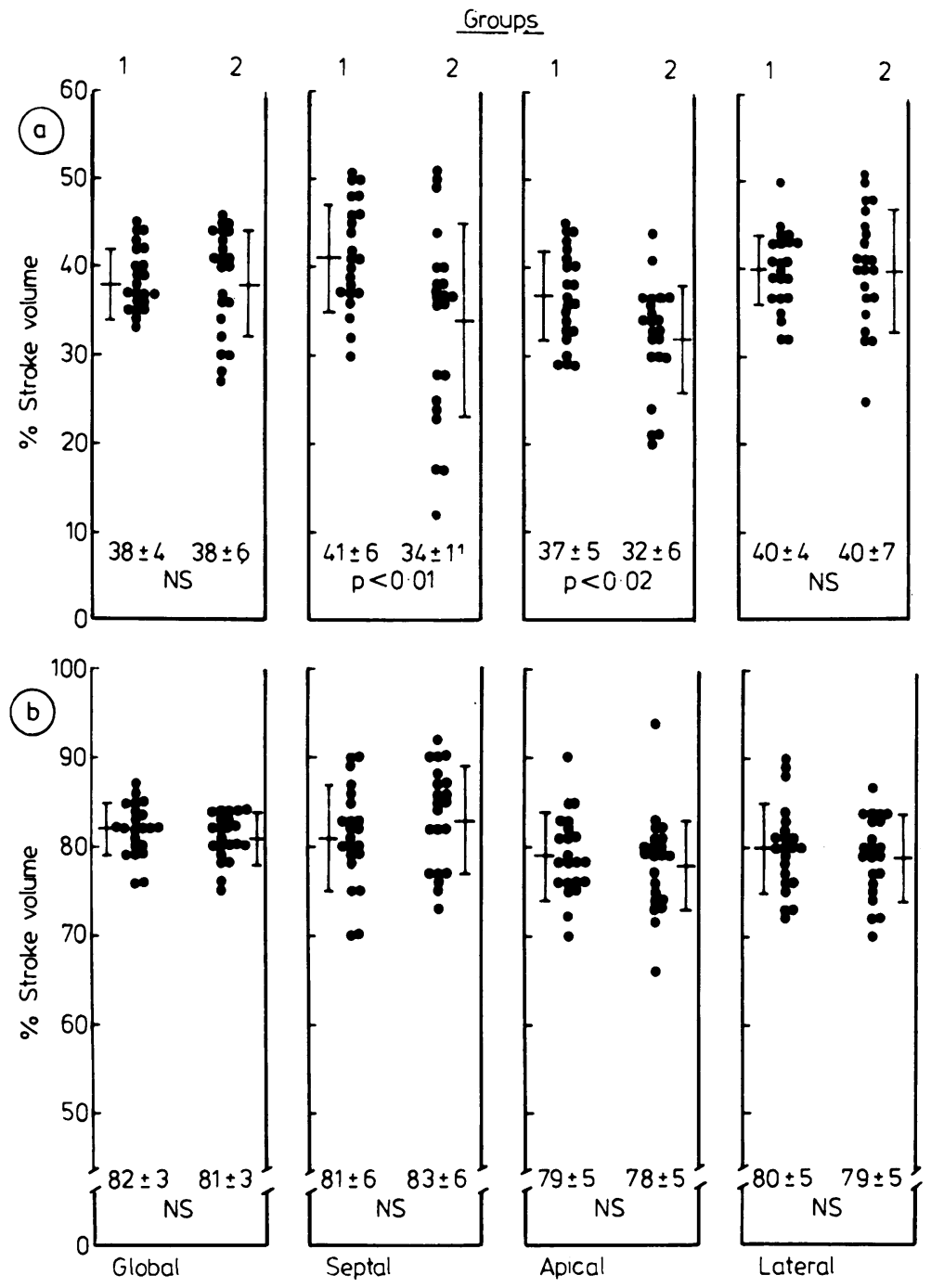

Fig. 2 Percentage stroke volume at the (a) first third and (b) second third of systole in patients with angina pectoris (group 2) and controls (group 1). Bars represent means $\pm S D$.

contributed $0.08 \pm 0.06 \mathrm{~cm},{ }^{18}$ which was small relative to the segmental motion of the left ventricle. Thus it is reasonable to assume from this that using the centre of gravity as a reference point results in the least error.

\section{Results}

Tables 1 and 2 show the radionuclide data for groups 1 and 2 . The mean resting heart rate in group 2 was significantly lower than that in group $1(73 \pm 12$ $v 67 \pm 9$ beats/minute; $p<0.05$ ). The mean age in group 2 was significantly greater than that in group 1 $(46 \pm 14 v 58 \pm 5$ year; $\mathrm{p}<0.001)$. Pre-ejection period in group 2 was significantly greater than that in group $1(86 \pm 14 v 110 \pm 18 \mathrm{~ms} ; \mathrm{p}<0.001)$.

\section{SYSTOLIC PHASE INDEXES}

Ejection fraction was not significantly different between groups 1 and 2 in the global left ventricle $(58 \pm 3 \%$ v $58 \pm 6 \%$, NS), or in the septal $(55 \pm 8 \% v$ $57 \pm 9 \%$; NS), apical ( $85 \pm 8 \%$ v $86 \pm 10 \%$; NS), or lateral $(67 \pm 10 \%$ v $69 \pm 11 \%$; NS) regions (Table 1$)$. Time to end systole was also not significantly different between groups 1 and 2 in the global left ventricle $(349 \pm 31 v 356 \pm 35 \mathrm{~ms} ; \mathrm{NS})$, or in the septal $(344 \pm 31$ $v 347 \pm 42 \mathrm{~ms} ; \mathrm{NS})$, apical $(357 \pm 33 v 364 \pm 33 \mathrm{~ms}$; 
$\mathrm{NS})$, or lateral $(357 \pm 30 v 373 \pm 31 \mathrm{~ms} ; \mathrm{NS})$ regions (Table 1).

End systole of each region occurred within $40 \mathrm{~ms}$ after or before the global end systole in both groups. When time to end systole in one region was compared with that in the other in the same group, there was no significant difference in regional time to end systole among the three different regions in either group. To compare the time interval from the global end systole to the regional end systole when heart rates vary its interval was normalised by dividing it by the time interval from the electrocardiogram $R$ wave to the global end systole and expressing the result as a percentage. There were no significant differences in this value between the two groups in the septal $(4 \pm 3 \% v$ $5 \pm 3 \%$; NS), apical ( $3 \pm 3 \% v 3 \pm 3 \%$; NS), and lateral $(3 \pm 2 \%$ v $5 \pm 5 \%$; NS) regions.

The percentage stroke volume at the first third of systole in group 2 was significantly lower than that in group 1 in the septal $(41 \pm 6 \% v 34 \pm 11 \% ; p<0.01)$ or apical $(37 \pm 5 \% v 32 \pm 6 \% ; \mathrm{p}<0.02)$ regions, while there was no significant difference between that in the two groups in the global left ventricle $(38 \pm 4 \% v$ $38 \pm 6 \%$; NS) or lateral $(40 \pm 4 \%$ v $40 \pm 7 \%$; NS) regions (Fig. 2, Table 1). In group 2, the percentage stroke volume at the first third of systole was outside the lower normal limits (global, 30; apical, 27; septal, 29; and lateral $32 \%$ ) in four patients (18\%) in the global left ventricle and in eight patients $(36 \%)$ in the septal, in four patients (18\%) in the apical, and in one patient $(5 \%)$ in the lateral regions. In contrast, the percentage stroke volume at the second third of systole was not significantly different between the two groups in the global left ventricle $(82 \pm 3 v 81 \pm 3 \%$; NS), or in the septal $(81 \pm 6 v 83 \pm 6 \%$; NS), apical $(79 \pm 5 v 78 \pm 5 \%$; NS), or lateral $(80 \pm 5 v 79 \pm 5 \%$; NS) regions (Fig. 2, Table 1). In group 2, the percentage stroke volume at the second third of systole was within normal lower limits in the global left ventricle and in each region.

\section{REPRODUCIBILITY OF RADIONUCLIDE TECHNIQUE}

Table 2 shows the reproducibility of the technique. There was excellent correlation between the global systolic variables obtained from the first and second studies $(r \geqslant 0.94)$ and between the regional systolic variables obtained from the first and second studies $(r \geqslant 0.90)$.

\section{Discussion}

\section{GLOBAL LEFT VENTRICLE}

There was no significant difference in ejection fraction, time to end systole, or the percentage stroke volume at the second third of systole between the two groups. The percentage stroke volume at one third systole was also not significantly different between the two groups. Similar results showing that early ejection phase indices could not identify minor abnormalities of left ventricular function in patients with angina pectoris have been reported by Kemper et al, ${ }^{3}$ Jones et $a l,{ }^{4}$ Hoshino et al, ${ }^{5}$ Sonnemaker $e t ~ a l,{ }^{6}$ Denenberg et $a l,{ }^{7}$ and Narita et al ${ }^{8}$ In contrast, studies by Adams et $a l,{ }^{2}$ Johnson et al, ${ }^{9}$ Slutsky et al, 1011 and Holman et $a l^{12}$ provided data suggesting that various measures of the early ejection phase are often abnormal, even when all the pansystolic indices are normal (Table 3). As shown in Table 3, this difference might be derived from the differences in technique, in the populations studied, or in the methods used for dividing the systolic interval into several sections. Johnson et al, ${ }^{9}$ Slutsky et al, ${ }^{11}$ and Holman et al ${ }^{12}$ divided the interval between end diastole and end systole into thirds and calculated the ejection fraction at the first third.

In contrast, Kemper et al, ${ }^{3}$ Hoshino et al, ${ }^{5}$ Narita et

Table 3 Reported values for percentage stroke volume at the first third of systole by various techniques

\begin{tabular}{|c|c|c|c|c|c|c|c|}
\hline & \multirow[t]{2}{*}{ Techrique } & \multicolumn{2}{|l|}{ Ejection } & \multirow[t]{2}{*}{ Control } & \multirow[t]{2}{*}{$C A D$} & & \multirow[t]{2}{*}{$M I$} \\
\hline & & Beginning & End & & & & \\
\hline $\begin{array}{l}\text { Adams et } a l^{2} \\
\text { Kemper et } a l^{3} \\
\text { Jones et } a l^{4} \\
\text { Hoshino et } a l^{5} \\
\text { Narita et } a l^{8} \\
\text { Johnson et } a l^{9} \\
\text { Slutsky et } a l^{10} \\
\text { Slutsky et } a l^{11} \\
\text { Holman et al }{ }^{12} \\
\text { Present study }\end{array}$ & $\begin{array}{l}\text { CS echo } \\
\text { Cine } \\
\text { RI (first) } \\
\text { Cine } \\
\text { Cine } \\
\text { RI (gated) } \\
\text { Cine } \\
\text { Cine } \\
\text { RI (first) } \\
\text { RI (gated) } \\
\text { RI (gated) }\end{array}$ & $\begin{array}{l}\text { PEP } \\
\text { Max } \\
\text { PEP } \\
\text { PEP } \\
\text { Max } \\
\text { PEP } \\
\text { Max } \\
\text { Max } \\
\text { PEP }\end{array}$ & $\begin{array}{l}\text { Min } \\
\text { Min } \\
\text { Min } \\
\text { Min } \\
\text { Min } \\
\text { Min } \\
\text { Min } \\
\text { Min } \\
\text { Min }\end{array}$ & $\begin{array}{l}0.41 \\
0.41 \\
0.30 \\
0.43 \\
0.40 \\
0.27 \\
0.44 \\
0.51 \\
0.47 \\
0.53 \\
0.39\end{array}$ & $\begin{array}{l}0.26 \\
0.42 \\
0.26 \\
0.37 \\
0.23 \\
0.28 \\
\\
0.31 \\
0.44 \\
0.38\end{array}$ & $0.32^{\star}$ & $\begin{array}{l}0.45 \\
0.28 \\
0.39 \\
0.32 \\
0.20\end{array}$ \\
\hline
\end{tabular}

Cine, cineventriculography; first, first pass radionuclide ventriculography; gated, ECG gated radionuclide ventriculography; max, maximum counts or volume; min, minimum counts or volume; PEP, at the end of pre-ejection period; CS echo, cross sectional echocardiography; CAD, patients with coronary artery disease but with normal wall motion; MI, patients with myocardial infarction with depressed resting ejection fraction or wall motion abnormality.

$\star$ Includes patients in both groups 
$a l,{ }^{8}$ and ourselves divided the interval between the end of the pre-ejection period and end systole into thirds and calculated the percentage stroke volume at the first third of systole. Prolongation of the preejection period is well known to be present in patients with coronary artery disease. ${ }^{16}$ Our results in patients with angina pectoris also showed significant prolongation of the pre-ejection period compared with that in the control subjects. The pre-ejection period can therefore affect appreciably the ejection fraction or the percentage stroke volume at the first third of systole. If the interval between end diastole and end systole is divided into thirds, the ejection fraction or the percentage stroke volume at the first third is decreased in patients with prolongation of the preejection period. Thus the ejection time, which is the interval between the end of the pre-ejection period and end systole, should be divided into thirds.

\section{REGIONAL LEFT VENTRICLE}

There was no significant difference between the two groups in the ejection fraction or the percentage stroke volume at the second third of systole in each region of the left ventricle. There was also no significant difference between these two groups in the time to end systole in each region. The time interval between the global and regional end systole was short relative to the interval between the electrocardiogram $\mathbf{R}$ wave and the global end systole in group 2 as well as in group 1. This indicates that regional end systole occurs close to the global end systole and that each region in group 2 as well as group 1 completes shortening at nearly the same time. A similar finding has been observed by Holman et al. ${ }^{12}$

In group 2, the percentage stroke volume at the first third of systole was significantly lower in the side perfused by the stenosed vessel (septal and apical regions) than those in group 1, whereas there was no significant difference in this value in the normally perfused side (lateral) between the two groups. Fig. 3 shows typical global and regional percentage stroke volume curves in a control subject (group 1) and in a patient with angina pectoris (group 2), in which maximum counts were expressed as $100 \%$ and minimum counts as $0 \%$ during the interval between end diastole and end systole of the global left ventricle. In some patients in group 2 who had a lower percentage stroke volume at the first third of systole in the global left ventricle, contraction delay during early systole, as shown by the arrow in Fig. 3, was observed in the side perfused by the stenosed vessel. Abnormal wall motion during early systole has been well known in patients with angina pectoris or in patients with myocardial infarction.121323 The patients in this study had had no previous myocardial infarction, and resting myocardial scintigraphy with

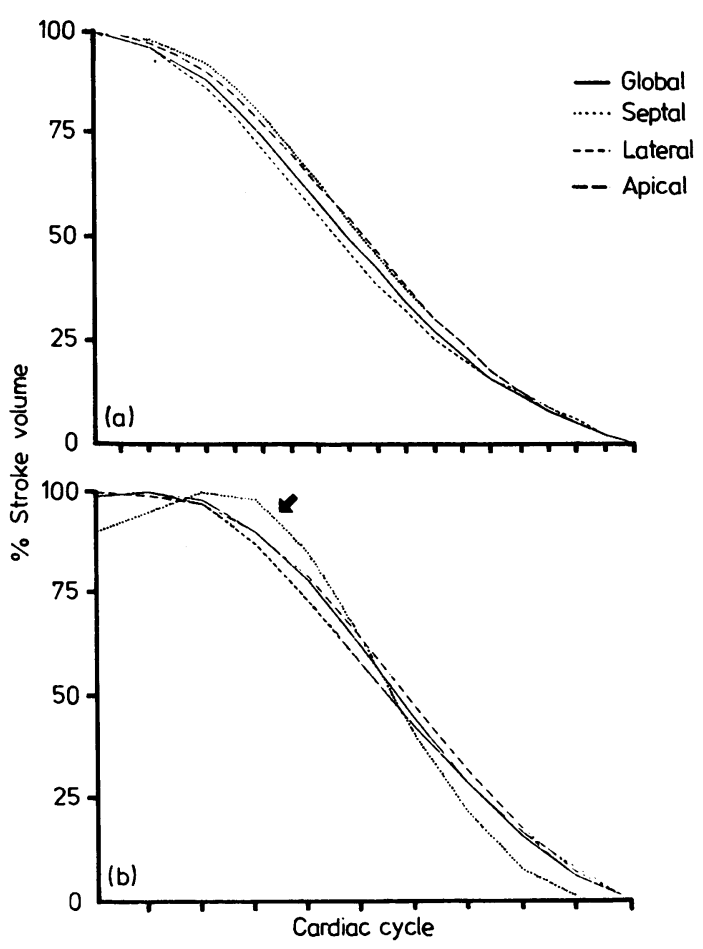

Fig. 3 Typical percentage stroke volume curve from (a) a control subject (group 1) and (b) a patient with angina pectoris (group 2). Arrow indicates contraction delay during early systole.

thallium-201 showed no uptake defects in any of the patients. Repeated anginal episodes can, however, produce small foci of myocardial necrosis. ${ }^{24}$ Small foci of myocardial necrosis - too small to be detected by resting myocardial scintigraphy-may cause contraction delay and impairment of ejection during early systole in the side perfused by the stenosed vessel. Thus asynchronous regional contraction between the side perfused by the stenosed vessel and the normally perfused side occurs during early systole. In the present study, the percentage of the stroke volume ejected during the first third of ejection time in the global left ventricle was similar in control subjects and in patients with angina pectoris. In patients with angina pectoris, however, when eight patients with a lower value $(<29 \%$ lower limit of normal value in the septal region) of the percentage stroke volume at the first third of systole in the septal region were compared with 14 patients without this abnormal value, the former had significantly lower values of the percentage stroke volume at the first third of systole in the global left ventricle than the latter $(31 \pm 3 \% v 41 \pm 5 \%$; $\mathrm{p}<0.001$ ). This indicates that an early contraction abnormality in the side perfused by the stenosed ves- 
sel disturbs the ejection during early systole of the global left ventricle. Thus an analysis of the regional change in left ventricular volume during ejection in patients with coronary artery disease could show localised areas of contraction abnormalities during early systole that are not apparent when ventricular contraction is evaluated as a whole.

We thank Drs A Arima, A Matsura, and K Nisiuc for their invaluable technical assistance in performing these studies.

\section{References}

1 Noble MIM, Trenchard D, Guz A. Left ventricular ejection in conscious dogs: I. Measurement and significance of the maximum acceleration of blood from the left ventricle. Circ Res 1966; 19: 139-47.

2 Adams J, Rahimtoola S, Schiller N, Bristow JD. Subclinical abnormalities of left ventricular function in coronary patients detected by 2-D echo [Abstract]. Am $\mathcal{F}$ Cardiol 1980; 45: 404.

3 Kemper AJ, Bianco JA, Shulman RM, Folland ED, Parisi AF, Tow DE. The interval ejection fraction: a cineangiographic and radionuclide study. Circulation 1982; 65: 1094-9.

4 Jones AA, Goodyer AVN, Cohen LS, Langou RA. Lack of sensitivity of the first third resting ejection fraction for identifying patients with coronary artery disease $[\mathrm{Ab}$ stract]. Circulation 1980; 62 (suppl III): 78.

5 Hoshino T, Tomonaga G, Motomura M, Shimono Y, Kinoshita M, Kusukawa R. Quantitative analysis of left ventricular ejection phase by means of left ventricular cineangiography. Fpn Circ $\mathcal{F}$ 1977; 41: 1085-97.

6 Sonnemaker RE, DePuey EG, Floyd JL, Thompson WL, Burdine JA. Left ventricular function assessment of patients with coronary artery disease [Abstract]. $\mathcal{F} \mathrm{Nucl}$ Med 1979; 20: 667.

7 Denenberg BS, Makler PT, Bove AA, Spann JF. Normal left ventricular emptying in coronary artery disease at rest: analysis by radiographic and equilibrium radionuclide ventriculography. Am $\mathcal{F}$ Cardiol 1981; 48: 311-5.

8 Narita $M$, Kurihara T, Murano K, Usami M, Honda $M$, Kanao K. Evaluation of various systolic phase indices in ischeamic heart disease by cardiac pool imaging [Japanese with English abstract]. Kaku Igaku 1982; 19: 409-17.

9 Johnson LL, Ellis K, Schmidt D, Weiss MB, Cannon PJ. Volume ejected in early systole: a sensitive index of left ventricular performance in coronary artery disease. Circulation 1975; 52: 378-89.

10 Slutsky R, Karliner JS, Battler A, Peterson K, Ross J Jr. Comparison of early systolic and holosystolic ejection phase indexes by contrast ventriculography in patients with coronary artery disease. Circulation 1980; 61: 1083-90.

11 Slutsky R, Gordon D, Karliner JS, et al. Assessment of early ventricular systole by first pass radionuclide angiography: useful method for detection of left ventricular dysfunction at rest in patients with coronary aretery disease. Am ₹ Cardiol 1979; 44: 459-65.

12 Holman BL, Wynne J, Idoine J, Neill J. Disruption in the temporal sequence of regional ventricular contraction. I. Characteristics and incidence in coronary artery disease. Circulation 1980; 61: 1075-83.

13 Leighton RF, Pollack MEM, Welch TG. Abnormal left ventricular wall motion at mid-ejection in patients with coronary heart disease. Circulation 1975; 52: $238-44$.

14 Papapietro SE, Yester MV, Logic JR, et al. Method for quantitative analysis of regional left ventricular function with first pass and gated blood pool scintigraphy. Am $\mathcal{F}$ Cardiol 1981; 47: 618-25.

15 Pfisterer M, Glaus L, Burkart F. Comparative effects of nitroglycerin, nifedipine and metoprolol on regional left ventricular function in patients with one-vessel coronary disease. Circulation 1983; 67: 291-301.

16 Weissler AM, Harris WS, Schoenfeld CD. Bedside technics for the evaluation of ventricular function in man. Am F Cardiol 1969; 23: 577-83.

17 Clayton PD, Jeppson GM, Klausner SC. Should a fixed external reference system be used to analyse left ventricular wall motion? Circulation 1982; 65: 1518-21.

18 Ingels NB Jr, Daughters GT II, Stinson EB, Alderman EL. Evaluation of methods for quantitating left ventricular segmental wall motion in man using myocardial markers as a standard. Circulation 1980; 61: 966-72.

19 Pearlman AS, Clark CE, Henry WL, Morganroth J, Itscoitz SB, Epstein SE. Determinants of ventricular septal motion: influence of relative right and left ventricular size. Circulation 1976; 54: 83-91.

20 Ingels NB Jr, Mead C, Daughters GT II, Stinson EB, Alderman EL. Cardiac dynamics. The Hague, Boston, London: Martinus Nijhoff, 1980: 417-31.

21 Rickards A, Seabra-Gomes R, Thurston P. The assessment of regional abnormalities of the left ventricle by angiography. Eur $\mathcal{F}$ Cardiol 1977; 5: 167-82.

22 Heintzen PH, Moldenhauer K, Lange PE. Threedimensional computerized contraction pattern analysis: description of methodology and its validation. Eur $\mathcal{f}$ Cardiol 1977; 1: 229-39.

23 Gibson DG, Doran JH, Traill TA, Brown DJ. Abnormal left ventricular wall movement during early systole in patients with angina pectoris. $\mathrm{Br}$ Heart $\mathcal{F}$ 1978; 40: 75866.

24 Geft IL, Fishbein MC, Ninomiya K, et al. Intermittent brief periods of ischemia have a cumulative effect and may cause myocardial necrosis. Circulation 1982; 66: 1150-3. 